\title{
Associations of Metabolic Syndrome with Total Testosterone and Homocysteine Levels in Male Korean
} Workers

\author{
Sook Hee Sung, Nam Hee Kim, Sun Pyo Hong, Jong-Keun Lee, Seung Jin Choi \\ Radiation Health Institute, Korea Hydro and Nuclear Power Co., Ltd., Seongnam, Korea
}

Background: Low testosterone is associated with metabolic syndrome (MetS), and homocysteine (Hcy) is elevated in individuals with MetS. We investigated the relationships of total testosterone (TT) and serum Hcy levels with MetS in male Korean workers.

Methods: We conducted a cross-sectional study including 8,606 male workers, aged 20 to 58 years, who underwent a physical examination in 2015. MetS was diagnosed based on the criteria of the 2009 harmonized definition, while the Korean standard for waist circumference (WC) was used. Participants' biochemical parameters, including TT and serum Hcy, were measured, and participants were divided into quartiles. Multiple logistic regression models were used to estimate the association of MetS and its individual components depending on TT and serum Hcy quartiles.

Results: The prevalence of MetS in the study population was 16\%. TT was lower in participants with MetS than in those without MetS $(P<0.001)$. By contrast, Hcy level was similar between groups $(P=0.694)$. In multiple logistic regression analysis, the odds ratio for the lowest TT quartile was 1.29 (95\% confidence interval, 1.06 to 1.57$)$ after adjusting for potential confounders. Participants with lower TT were more likely to have high WC, hypertriglyceridemia, and low high density lipoprotein levels. Serum Hcy levels were not significantly associated with MetS. Of the five components of MetS, only WC was significantly associated with serum Hcy.

Conclusion: In male Korean workers, TT may be an independent predictor of MetS, and serum Hcy levels could be a marker of abdominal obesity. However, future prospective studies are needed.

Keywords: Testosterone; Homocysteine; Metabolic syndrome; Odds ratio

\section{INTRODUCTION}

The prevalence of metabolic syndrome (MetS) has increased worldwide in recent decades and has become an important public health problem globally. In Korea, the prevalence of MetS increased from an age-standardized rate of $24.9 \%$ in 1998 to $31.3 \%$ in 2007 [1]. MetS is diagnosed when a patient has a clus- ter of cardiovascular risk factors, including abdominal obesity, hypertriglyceridemia, low high density lipoprotein cholesterol (HDL-C) levels, hyperglycemia, and hypertension. MetS patients are at an elevated risk of cardiovascular disease (CVD) and type 2 diabetes mellitus (DM) [2].

Several epidemiological studies have linked low total testosterone (TT) level to MetS [3-5]. Some prospective studies have
Received: 19 January 2019, Revised: 8 March 2019, Accepted: 12 March 2019

Corresponding author: Seung Jin Choi

Radiation Health Institute, Korea Hydro and Nuclear Power Co., Ltd., 172 Dolma-ro, Bundang-gu, Seongnam 13605, Korea

Tel: +82-31-289-3560, Fax: +82-31-289-3569, E-mail: sjchoice@naver.com
Copyright $\odot 2019$ Korean Endocrine Society

This is an Open Access article distributed under the terms of the Creative Commons Attribution Non-Commercial License (http://creativecommons.org/ licenses/by-nc/4.0/) which permits unrestricted non-commercial use, distribution, and reproduction in any medium, provided the original work is properly cited. 
demonstrated that low TT levels predict MetS development $[6,7]$. Furthermore, both cross-sectional and longitudinal studies have reported that low TT levels are associated with increased fat deposition, resulting in insulin resistance and abdominal obesity $[8,9]$. This bidirectional relationship leads to the development of MetS, as well as type 2 DM and CVD [10].

Homocysteine (Hcy) is involved in the metabolism of methionine as a sulfur-containing amino acid. Hyperhomocysteinemia is an independent risk factor for atherosclerosis and is induced by endothelial dysfunction, smooth muscle cell proliferation, oxidative stress, and hemostasis [11]. Thus, it can cause CVD and cerebrovascular disease [12]. Hyperhomocysteinemia is also associated with insulin resistance and MetS, although some studies have reported conflicting findings $[13,14]$.

The relationship between MetS and TT or serum Hcy levels has been studied in different populations worldwide. It is necessary to study larger populations with diverse characteristics. In this study, we investigated whether TT and serum Hcy levels were associated with MetS and metabolic components and whether they could be used as predictors of MetS among male Korean workers, as a population different from those investigated in previous studies.

\section{METHODS}

\section{Subjects}

This cross-sectional study enrolled male Korean industrial workers who underwent an annual health check-up in 2015. The study population included 8,769 men aged 20 to 58 years. From this population, individuals who were taking testosterone or steroidal agents that could affect serum testosterone level or who had neoplastic, severe liver, or renal disease were excluded. A total of 8,606 men were included in this analysis. The study was approved by the Institutional Review Board of Hanil Hospital, Seoul, Korea (2014-H-001), and written informed consent was obtained from each participant.

\section{Measurements}

Participants fasted for at least 8 hours before the study. Body weight, height, and blood pressure (BP) were measured using standard techniques. Body mass index (BMI) was calculated as weight $(\mathrm{kg})$ divided by height squared $\left(\mathrm{m}^{2}\right)$. Waist circumference (WC) was measured at the level midway between the lowest rib and the iliac crest. Fasting blood samples were collected from the antecubital vein and analyzed biochemically and immunologically using a Cobas c702 module (Cobas, Roche Di- agnostics, Basel, Switzerland). Fasting plasma glucose (FPG) levels were measured using an enzymatic reference method with hexokinase. Triglyceride (TG) and uric acid (UA) levels were measured using an enzymatic colorimetric method. Low density lipoprotein cholesterol (LDL-C) and HDL-C levels were assessed using a homogeneous, enzymatic, colorimetric assay. Serum creatinine levels were measured using a kinetic colorimetric assay. Serum high-sensitivity C-reactive protein (hs-CRP) levels were assayed by particle-enhanced immunoturbidimetry. TT levels were measured by a radioimmunoassay using DIAsource TESTO-RIA-CT Kits (DIAsource ImmunoAssays S.A., Louvain-la-Neuve, Belgium); the intra-assay coefficient of variance $(\mathrm{CV})$ was $3.3 \%$ to $4.6 \%$, and the inter-assay $\mathrm{CV}$ was $4.8 \%$ to $6.2 \%$. Liquid stable 2-part homocysteine reagent kits and an Axis-Shield Calibrator (Axis-Shield Diagnostics Ltd., Dundee, Scotland United Kingdom) were used to determine serum Hcy levels. The intra-assay and inter-assay CV was $1.3 \%$ to $2.1 \%$ and $1.1 \%$ to $1.3 \%$, respectively. Insulin levels were measured using $\left[{ }^{125} \mathrm{I}\right]$ immunoradiometric assay (IRMA) Kits. Homeostasis model assessment of insulin resistance (HOMA-IR) was calculated using the following equation: [glucose $(\mathrm{mg} / \mathrm{dL}) \times$ insulin $(\mu \mathrm{U} / \mathrm{mL})] / 405$. All participants completed a questionnaire on health-related behavior. Behavioral risk factors included smoking status (non-smoker, former smoker, or current smoker), alcohol consumption (non-drinker or drinker; drinkers defined as those who consumed alcohol more than once a week), and exercise. Exercise was defined as above recommended physical activity (PA) if an individual engaged in moderately intense aerobic PA (e.g., badminton or ping-pong) for at least 20 minutes for 5 days a week; vigorously intense activity (e.g., running or mountain climbing) for at least $20 \mathrm{~min}$ utes 4 days a week; or walking for 20 minutes every day. Less intense levels of exercise were considered to be below recommended PA.

\section{Definition of MetS}

We defined MetS using criteria based on the 2009 harmonized definition [15]. A diagnosis of MetS was made if three of the following criteria were met: (1) WC $\geq 90 \mathrm{~cm}$; (2) TG $\geq 150 \mathrm{mg} / \mathrm{dL}$ or receiving medical treatment for elevated TG levels; (3) HDL$\mathrm{C}<40 \mathrm{mg} / \mathrm{dL}$; (4) BP $\geq 130 / 85 \mathrm{~mm} \mathrm{Hg}$ or current use of antihypertensive medications; (5) FPG $\geq 100 \mathrm{mg} / \mathrm{dL}$ or receiving treatment for previously diagnosed type $2 \mathrm{DM}$. The WC cut-off was set in accordance with the ethnically appropriate abdominal obesity criteria for Koreans as put forth by the Korean Society for the Study of Obesity [16]. 


\section{Statistical analysis}

The characteristics of participants are summarized as mean \pm standard deviation for continuous variables or as frequencies and percentages for categorical variables. Comparisons of participants with and without MetS were performed using the Student $t$ tests for continuous variables and the chi-square test for categorical variables. Pearson correlation analysis was applied to evaluate the correlations between TT or serum Hcy level and continuous variables, and Spearman rank correlation analysis was used for categorical variables. Participants were divided into quartiles based on their TT level (Q1, $\leq 5.08 \mathrm{ng} / \mathrm{mL}$; Q2, 5.09 to $6.23 \mathrm{ng} / \mathrm{mL}$; Q3, 6.24 to $7.64 \mathrm{ng} / \mathrm{mL}$; and Q4, $\geq 7.65 \mathrm{ng} / \mathrm{mL}$ ) and serum Hcy level (Q1, $\geq 12.21 \mu \mathrm{mol} / \mathrm{L} ; \mathrm{Q} 2,10.51$ to $12.10 \mu \mathrm{mol} / \mathrm{L}$; Q3, 9.11 to $10.50 \mu \mathrm{mol} / \mathrm{L}$; and $\mathrm{Q} 4, \leq 9.10 \mu \mathrm{mol} / \mathrm{L}$ ). The effects of TT and serum Hcy quartile were tested using analysis of variance (ANOVA) for continuous variables and the Kruskal-Wallis test for dichotomous variables. We also performed multiple logistic regression analyses to evaluate associations between TT and serum Hcy quartiles and the prevalence of MetS. Age, alcohol consumption, smoking status, hs-CRP, HOMA-IR, and BMI were included to investigate the influence of potential confounders. Odds ratios (ORs) and 95\% confidence intervals (CIs) were estimated to determine the risk of MetS for each quartile. In addition, we examined the association between TT and serum Hcy quartiles and each MetS component separately. All analyses were conducted using SPSS for Windows version 15.0 (SPSS Inc., Chicago, IL, USA). $P$ values $<0.05$ were considered statistically significant.

\section{RESULTS}

\section{Characteristics of the study population}

The clinical characteristics of the study participants are presented in Table 1. The mean age of participants with MetS and without MetS was 45.1 \pm 8.2 and 39.9 \pm 9.4 years, respectively $(P<$ $0.001)$. The prevalence of MetS in the study population was $16 \%$. TT levels were significantly lower in individuals with MetS than in those without MetS $(P<0.001)$. Serum Hcy levels were not significantly different according to the presence of MetS $(P=$ 0.694). However, WC, BMI, BP, FPG, TG, LDL-C, HOMA-IR, hs-CRP, alcohol consumption status, and smoking status were significantly higher in individuals with MetS $(P<0.001)$. There was no significant difference in PA between groups $(P=0.097)$, but HDL-C levels were significantly lower in individuals with MetS $(P<0.001)$.

\section{Relationships of clinical characteristics with TT and serum Hcy levels}

TT levels were correlated with all variables except smoking status. Serum Hcy levels, in contrast, showed significant correlations only with UA, FPG, LDL-C, and smoking status. Unlike what was observed for TT levels, there was an almost negligible correlation with age. Furthermore, TT and serum Hcy levels

Table 1. General Characteristics of Study Participants $(n=$ $8,606)$

\begin{tabular}{|c|c|c|c|}
\hline Characteristic & $\begin{array}{c}\text { Men without } \\
\text { MetS } \\
(n=7,037)\end{array}$ & $\begin{array}{l}\text { Men with } \\
\text { MetS } \\
(n=1,569)\end{array}$ & $P$ value \\
\hline Age, yr & $39.9 \pm 9.4$ & $45.1 \pm 8.2$ & $<0.001$ \\
\hline Waist circumference, $\mathrm{cm}$ & $82.3 \pm 6.5$ & $90 \pm 7$ & $<0.001$ \\
\hline BMI, $\mathrm{kg} / \mathrm{m}^{2}$ & $23.9 \pm 2.6$ & $26.8 \pm 2.9$ & $<0.001$ \\
\hline $\mathrm{SBP}, \mathrm{mm} \mathrm{Hg}$ & $117.8 \pm 10.1$ & $127.1 \pm 12.1$ & $<0.001$ \\
\hline DBP, $\mathrm{mm} \mathrm{Hg}$ & $75.6 \pm 8.6$ & $82.7 \pm 9.3$ & $<0.001$ \\
\hline Serum creatinine, $\mathrm{mg} / \mathrm{dL}$ & $0.9 \pm 0.1$ & $0.9 \pm 0.2$ & 0.630 \\
\hline $\mathrm{FPG}, \mathrm{mg} / \mathrm{dL}$ & $94.4 \pm 13.4$ & $109.2 \pm 23.5$ & $<0.001$ \\
\hline Insulin, $\mathrm{ng} / \mathrm{mL}$ & $6 \pm 4$ & $9.6 \pm 6.8$ & $<0.001$ \\
\hline Uric acid, mg/dL & $5.9 \pm 1.2$ & $6.3 \pm 1.3$ & $<0.001$ \\
\hline LDL-C, mg/dL & $124 \pm 30$ & $130.1 \pm 33$ & $<0.001$ \\
\hline $\mathrm{HDL}-\mathrm{C}, \mathrm{mg} / \mathrm{dL}$ & $53.9 \pm 12.7$ & $43 \pm 10.7$ & $<0.001$ \\
\hline $\mathrm{TG}, \mathrm{mg} / \mathrm{dL}$ & $115.8 \pm 68.6$ & $215.7 \pm 121.7$ & $<0.001$ \\
\hline HOMA-IR & $1.4 \pm 1.1$ & $2.6 \pm 2.1$ & $<0.001$ \\
\hline hs-CRP, mg/dL & $0.09 \pm 0.33$ & $0.13 \pm 0.35$ & $<0.001$ \\
\hline Total testosterone, $\mathrm{ng} / \mathrm{mL}$ & $6.6 \pm 2$ & $5.8 \pm 1.8$ & $<0.001$ \\
\hline Homocysteine, $\mu \mathrm{mol} / \mathrm{L}$ & $11.3 \pm 4.4$ & $11.3 \pm 4.2$ & 0.694 \\
\hline Smoking status & & & $<0.001$ \\
\hline Current smoker & $1,969(28.0)$ & $615(39.2)$ & \\
\hline Former smoker & $2,159(30.7)$ & $568(36.2)$ & \\
\hline Never smoker & $2,909(41.3)$ & $386(24.6)$ & \\
\hline Alcohol consumption & & & $<0.001$ \\
\hline$\leq$ Once a week & $4,878(69.3)$ & $961(61.2)$ & \\
\hline$\geq$ Twice a week & $2,159(30.7)$ & $608(38.8)$ & \\
\hline Exercise & & & 0.097 \\
\hline Below recommended PA & $4,814(68.4)$ & $1,107(70.6)$ & \\
\hline Above recommended PA & $2,223(31.6)$ & $462(29.4)$ & \\
\hline
\end{tabular}

Values are expressed as mean \pm SD or number (\%).

MetS, metabolic syndrome; BMI, body mass index; SBP, systolic blood pressure; DBP, diastolic blood pressure; FPG, fasting plasma glucose; LDL-C, low density lipoprotein cholesterol; HDL-C, high density lipoprotein cholesterol; TG, triglyceride; HOMA-IR, homeostatic model assessment of insulin resistance; hs-CRP, high-sensitivity C-reactive protein; PA, physical activity. 
showed reciprocally very weak correlations (Table 2). We analyzed clinical characteristics, including the individual components of MetS, depending on TT and serum Hcy quartiles using ANOVA (Table 3). Mean values for age, WC, BMI, BP, FPG, lipid levels, UA levels, hs-CRP, and HOMA-IR increased among lower TT quartiles, except for HDL-C, which exhibited an inverse relationship with TT quartile $(P<0.001)$. Higher serum Hcy quartiles were positively related to WC $(P=0.003)$, systolic BP $(P=0.008)$, UA $(P<0.001)$, and TG $(P=0.029)$. However, unexpectedly, FPG decreased in higher serum Hcy quartiles $(P=0.001)$. The number of MetS components and the prevalence of MetS were higher among participants with lower TT quartiles $(P<0.001)$ (Fig. 1). However, serum Hcy quartile was not significantly related with MetS prevalence $(P=0.361)$.

Table 2. Bivariate Analysis of the Correlations between Total Testosterone, Serum Homocysteine Levels, and Clinical Characteristics

\begin{tabular}{|c|c|c|c|c|}
\hline \multirow[t]{2}{*}{ Characteristic } & \multicolumn{2}{|c|}{$\begin{array}{c}\text { Total testosterone, } \\
\mathrm{ng} / \mathrm{mL}\end{array}$} & \multicolumn{2}{|c|}{$\begin{array}{c}\text { Serum homocysteine, } \\
\mu \mathrm{mol} / \mathrm{L}\end{array}$} \\
\hline & Coefficient & $P$ value & Coefficient & $P$ value \\
\hline Age, yr & -0.185 & $<0.001$ & -0.050 & $<0.001$ \\
\hline Waist circumference, $\mathrm{cm}$ & -0.266 & $<0.001$ & 0.003 & 0.761 \\
\hline BMI, $\mathrm{kg} / \mathrm{m}^{2}$ & -0.262 & $<0.001$ & 0.001 & 0.950 \\
\hline $\mathrm{SBP}, \mathrm{mm} \mathrm{Hg}$ & -0.066 & $<0.001$ & 0.008 & 0.444 \\
\hline DBP, $\mathrm{mm} \mathrm{Hg}$ & -0.056 & $<0.001$ & -0.014 & 0.206 \\
\hline Serum creatinine, $\mathrm{mg} / \mathrm{dL}$ & 0.018 & 0.094 & 0.178 & $<0.001$ \\
\hline FPG, mg/dL & -0.096 & $<0.001$ & -0.042 & $<0.001$ \\
\hline Insulin, ng/mL & -0.156 & $<0.001$ & 0.016 & 0.149 \\
\hline Uric acid, mg/dL & -0.067 & $<0.001$ & 0.103 & $<0.001$ \\
\hline LDL-C, mg/dL & -0.054 & $<0.001$ & -0.024 & 0.026 \\
\hline HDL-C, mg/dL & 0.255 & $<0.001$ & 0.005 & 0.631 \\
\hline $\mathrm{TG}, \mathrm{mg} / \mathrm{dL}$ & -0.178 & $<0.001$ & -0.020 & 0.061 \\
\hline HOMA-IR & -0.156 & $<0.001$ & 0.007 & 0.534 \\
\hline hs-CRP, mg/dL & -0.093 & $<0.001$ & 0.000 & 0.985 \\
\hline Smoking status & 0.002 & 0.883 & 0.042 & $<0.001$ \\
\hline Alcohol consumption & 0.052 & $<0.001$ & -0.007 & 0.542 \\
\hline Total testosterone, $\mathrm{ng} / \mathrm{mL}$ & & & 0.046 & $<0.001$ \\
\hline $\begin{array}{l}\text { Serum homocysteine, } \\
\mu \mathrm{mol} / \mathrm{L}\end{array}$ & 0.046 & $<0.001$ & & \\
\hline
\end{tabular}

BMI, body mass index; SBP, systolic blood pressure; DBP, diastolic blood pressure; FPG, fasting plasma glucose; LDL-C, low density lipoprotein cholesterol; HDL-C, high density lipoprotein cholesterol; TG, triglyceride; HOMA-IR, homeostatic model assessment of insulin resistance; hs-CRP, high-sensitivity C-reactive protein.

\section{Associations of MetS with TT and serum Hcy levels}

ORs with 95\% CIs for the prevalence of MetS depending on TT and serum Hcy quartiles are shown in Table 4. The highest TT and lowest serum Hcy quartiles were used as reference groups. Additive logistic regression models were customized to assess the potential confounding effect of various participant charac-
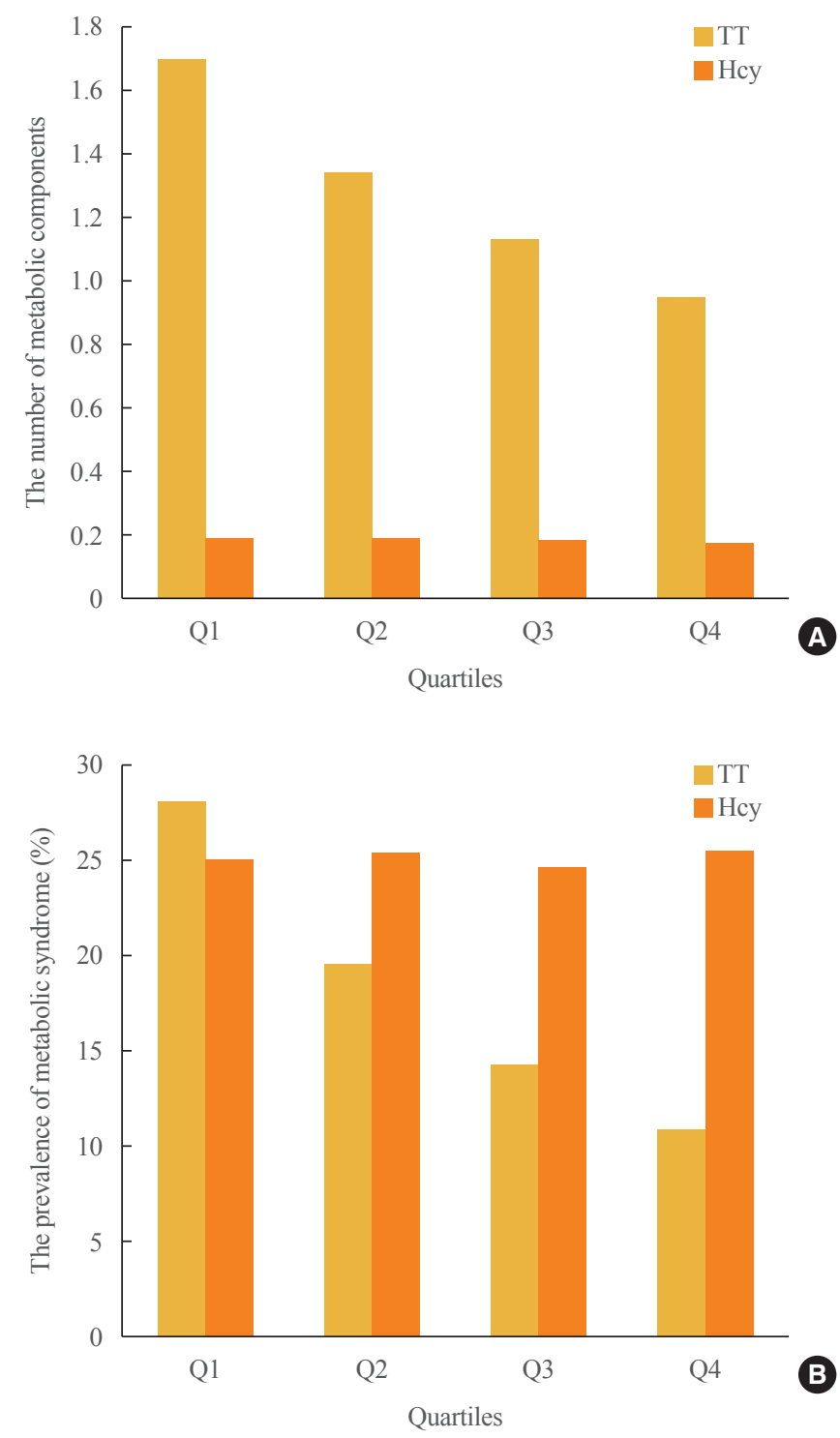

Fig. 1. Distribution of the prevalence of metabolic syndrome (MetS) and the number of MetS components depending on total testosterone (TT) and serum homocysteine (Hcy) quartiles in 8,606 male workers. (A) The number of MetS components was significantly different from the first (Q1) to the fourth (Q4) TT quartiles $(P<0.001)$. However, the number of MetS components was not related to serum Hcy quartile $(P=0.361)$. (B) The prevalence of MetS showed similar relationships with TT and serum Hcy quartiles $(P<0.001$ and $P=0.361$, respectively $)$. 
Table 3. Clinical Characteristics of Participants Based on Total Testosterone and Serum Homocysteine Level Quartiles

\begin{tabular}{|c|c|c|c|c|c|}
\hline Characteristic & Q1 & Q2 & Q3 & Q4 & $P$ trend \\
\hline \multicolumn{6}{|l|}{ Total testosterone $\mathrm{a}^{\mathrm{a}}$} \\
\hline No. of patients & 2,165 & 2,143 & 2,149 & 2,149 & \\
\hline Age, yr & $43.4 \pm 8.6$ & $41.5 \pm 9.0$ & $39.8 \pm 9.5$ & $38.7 \pm 9.8$ & $<0.001$ \\
\hline Waist circumference, $\mathrm{cm}$ & $86.3 \pm 7.4$ & $84.2 \pm 7.1$ & $83.2 \pm 6.9$ & $81 \pm 6.7$ & $<0.001$ \\
\hline BMI, $\mathrm{kg} / \mathrm{m}^{2}$ & $25.5 \pm 3.0$ & $24.7 \pm 2.8$ & $24.2 \pm 2.6$ & $23.5 \pm 2.6$ & $<0.001$ \\
\hline $\mathrm{SBP}, \mathrm{mm} \mathrm{Hg}$ & $120.6 \pm 11.7$ & $119.5 \pm 11.1$ & $119.1 \pm 11.3$ & $118.6 \pm 10.1$ & $<0.001$ \\
\hline DBP, $\mathrm{mm} \mathrm{Hg}$ & $77.8 \pm 9.3$ & $76.3 \pm 9.1$ & $7.6 \pm 9.2$ & $76.3 \pm 8.7$ & $<0.001$ \\
\hline FPG, $\mathrm{mg} / \mathrm{dL}$ & $99.8 \pm 20.5$ & $96.9 \pm 16.5$ & $96.1 \pm 14.6$ & $95.5 \pm 14.3$ & $<0.001$ \\
\hline Insulin, ng/mL & $7.9 \pm 6.4$ & $6.7 \pm 4.7$ & $6.2 \pm 3.8$ & $5.8 \pm 3.8$ & $<0.001$ \\
\hline Uric acid, mg/dL & $6.1 \pm 1.3$ & $6.0 \pm 1.2$ & $6.0 \pm 1.2$ & $5.9 \pm 1.2$ & $<0.001$ \\
\hline LDL-C, mg/dL & $127.3 \pm 30.5$ & $125.8 \pm 30.8$ & $124.2 \pm 30.8$ & $123.3 \pm 30.3$ & $<0.001$ \\
\hline HDL-C, mg/dL & $47.9 \pm 11.8$ & $50.2 \pm 12.2$ & $53.2 \pm 12.7$ & $56.4 \pm 13.8$ & $<0.001$ \\
\hline $\mathrm{TG}, \mathrm{mg} / \mathrm{dL}$ & $156.6 \pm 109.3$ & $139.2 \pm 89.2$ & $124.9 \pm 82.2$ & $115.01 \pm 67.0$ & $<0.001$ \\
\hline HOMA-IR & $2.0 \pm 1.9$ & $1.7 \pm 1.3$ & $1.5 \pm 1.1$ & $1.1 \pm 1.1$ & $<0.001$ \\
\hline hs-CRP, mg/dL & $0.15 \pm 0.54$ & $0.09 \pm 0.28$ & $0.07 \pm 0.17$ & $0.06 \pm 0.19$ & $<0.001$ \\
\hline \multicolumn{6}{|l|}{ Serum homocysteine ${ }^{\mathrm{b}}$} \\
\hline No. of patients & 2,100 & 2,065 & 2,128 & 2,313 & \\
\hline Age, yr & $40.4 \pm 9.9$ & $41.1 \pm 9.6$ & $40.9 \pm 9.3$ & $41.0 \pm 8.8$ & 0.055 \\
\hline Waist circumference, $\mathrm{cm}$ & $83.8 \pm 7.5$ & $84.1 \pm 7.4$ & $83.5 \pm 7.2$ & $83.4 \pm 7.0$ & 0.003 \\
\hline BMI, $\mathrm{kg} / \mathrm{m}^{2}$ & $24.5 \pm 2.9$ & $24.6 \pm 2.9$ & $24.4 \pm 2.9$ & $24.4 \pm 2.8$ & 0.094 \\
\hline SBP, $\mathrm{mm} \mathrm{Hg}$ & $120.1 \pm 11.1$ & $119.6 \pm 11.3$ & $119.1 \pm 11.3$ & $119.1 \pm 10.7$ & 0.008 \\
\hline DBP, $\mathrm{mm} \mathrm{Hg}$ & $77.1 \pm 9.4$ & $76.9 \pm 9.0$ & $76.6 \pm 8.9$ & $76.9 \pm 9.2$ & 0.407 \\
\hline FPG, $\mathrm{mg} / \mathrm{dL}$ & $95.9 \pm 16.3$ & $97.2 \pm 15.8$ & $97.2 \pm 15.8$ & $97.9 \pm 16.9$ & 0.001 \\
\hline Insulin, $\mathrm{ng} / \mathrm{mL}$ & $6.8 \pm 5.3$ & $6.7 \pm 5.0$ & $6.6 \pm 4.5$ & $6.6 \pm 4.6$ & 0.446 \\
\hline Uric acid, mg/dL & $6.2 \pm 1.3$ & $6.1 \pm 1.2$ & $6.0 \pm 1.2$ & $5.7 \pm 1.2$ & $<0.001$ \\
\hline LDL-C, mg/dL & $124.5 \pm 30.9$ & $125.0 \pm 30.6$ & $125.0 \pm 30.6$ & $125.2 \pm 30.1$ & 0.559 \\
\hline HDL-C, mg/dL & $51.9 \pm 13.0$ & $52.1 \pm 13.1$ & $51.8 \pm 13.1$ & $51.9 \pm 12.9$ & 0.889 \\
\hline $\mathrm{TG}, \mathrm{mg} / \mathrm{dL}$ & $132.4 \pm 92.8$ & $132.8 \pm 84.1$ & $131.6 \pm 78.9$ & $138.7 \pm 100.2$ & 0.029 \\
\hline HOMA-IR & $1.7 \pm 1.5$ & $1.7 \pm 1.5$ & $1.6 \pm 1.2$ & $1.6 \pm 1.4$ & 0.794 \\
\hline hs-CRP, mg/dL & $0.10 \pm 0.40$ & $0.10 \pm 0.29$ & $0.09 \pm 0.23$ & $0.10 \pm 0.37$ & 0.621 \\
\hline
\end{tabular}

Values are expressed as mean $\pm \mathrm{SD}$.

BMI, body mass index; SBP, systolic blood pressure; DBP, diastolic blood pressure; FPG, fasting plasma glucose; LDL-C, low density lipoprotein cholesterol; HDL-C, high density lipoprotein cholesterol; TG, triglyceride; HOMA-IR, homeostatic model assessment of insulin resistance; hs-CRP, highsensitivity C-reactive protein.

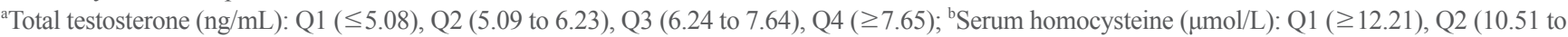
12.20), Q3 (9.11 to 10.50), Q4 ( $\leq 9.10)$.

teristics. The OR for MetS increased among lower TT quartiles. The unadjusted OR for MetS in the lowest TT quartile compared with the highest quartile was 3.18 (95\% CI, 2.67 to 3.80) in the crude model (model 1). After adjusting for confounding factors, including age (model 2), alcohol consumption and smoking status (model 3), hs-CRP (model 4), and HOMA-IR (model 5), the ORs for MetS in the lowest TT quartile did not significantly change. However, after adjusting for BMI (model 6), the OR decreased to 1.29 (95\% CI, 1.06 to 1.57$)$, which was a weakened but still significant association. By contrast, serum Hcy quartile was not significantly associated with MetS in any model. 
Table 4. Odds Ratios of Metabolic Syndrome Depending on Total Testosterone and Serum Homocysteine Quartiles

\begin{tabular}{|c|c|c|c|c|c|c|c|c|}
\hline & \multicolumn{4}{|c|}{ Total testosterone } & \multicolumn{4}{|c|}{ Serum homocysteine } \\
\hline & Q4 & Q3 & Q2 & Q1 & Q4 & Q3 & Q2 & Q1 \\
\hline Model 1 & 1.000 & & & & 1.000 & & & \\
\hline $\operatorname{Exp}(B)$ & & 1.415 & 2.024 & 3.184 & & 1.059 & 1.145 & 1.097 \\
\hline Lower & & 1.180 & 1.702 & 2.666 & & 0.908 & 0.982 & 0.941 \\
\hline Upper & & 1.697 & 2.407 & 3.803 & & 1.236 & 1.336 & 1.280 \\
\hline$P$ value & & $<0.001$ & $<0.001$ & $<0.001$ & & 0.464 & 0.084 & 0.237 \\
\hline Model 2 & 1.000 & & & & 1.000 & & & \\
\hline $\operatorname{Exp}(B)$ & & 1.354 & 1.806 & 2.644 & & 1.064 & 1.128 & 1.121 \\
\hline Lower & & 1.125 & 1.514 & 2.232 & & 0.908 & 0.964 & 0.957 \\
\hline Upper & & 1.628 & 2.154 & 3.132 & & 1.246 & 1.320 & 1.312 \\
\hline$P$ value & & $<0.001$ & $<0.001$ & $<0.001$ & & 0.443 & 0.133 & 0.157 \\
\hline Model 3 & 1.000 & & & & 1.000 & & & \\
\hline $\operatorname{Exp}(B)$ & & 1.376 & 1.862 & 2.801 & & 1.072 & 1.104 & 1.084 \\
\hline Lower & & 1.143 & 1.559 & 2.360 & & 0.915 & 0.943 & 0.924 \\
\hline Upper & & 1.657 & 2.225 & 3.323 & & 1.257 & 1.294 & 1.270 \\
\hline$P$ value & & $<0.001$ & $<0.001$ & $<0.001$ & & 0.388 & 0.219 & 0.322 \\
\hline Model 4 & 1.000 & & & & 1.000 & & & \\
\hline $\operatorname{Exp}(B)$ & & 1.374 & 1.854 & 2.766 & & 1.075 & 1.105 & 1.081 \\
\hline Lower & & 1.141 & 1.552 & 2.330 & & 0.917 & 0.943 & 0.922 \\
\hline Upper & & 1.654 & 2.214 & 3.283 & & 1.260 & 1.295 & 1.267 \\
\hline$P$ value & & 0.001 & $<0.001$ & $<0.001$ & & 0.375 & 0.215 & 0.339 \\
\hline Model 5 & 1.000 & & & & 1.000 & & & \\
\hline $\operatorname{Exp}(B)$ & & 1.304 & 1.662 & 2.125 & & 1.072 & 1.107 & 1.053 \\
\hline Lower & & 1.073 & 1.378 & 1.771 & & 0.905 & 0.935 & 0.888 \\
\hline Upper & & 1.584 & 2.004 & 2.549 & & 1.269 & 1.311 & 1.249 \\
\hline$P$ value & & 0.008 & $<0.001$ & $<0.001$ & & 0.423 & 0.240 & 0.551 \\
\hline Model 6 & 1.000 & & & & 1.000 & & & \\
\hline $\operatorname{Exp}(B)$ & & 1.062 & 1.226 & 1.294 & & 1.029 & 0.989 & 0.986 \\
\hline Lower & & 0.863 & 1.004 & 1.064 & & 0.859 & 0.825 & 0.821 \\
\hline Upper & & 1.306 & 1.497 & 1.573 & & 1.234 & 1.186 & 1.183 \\
\hline$P$ value & & 0.569 & 0.045 & 0.010 & & 0.753 & 0.906 & 0.877 \\
\hline
\end{tabular}

Model 1, crude odds ratios; Model 2, adjusted for age; Model 3, adjusted for model 2 plus alcohol consumption and smoking status; Model 4, adjusted for model 3 plus high-sensitivity C-reactive protein; Model 5, adjusted for model 4 plus homeostatic model assessment-insulin resistance; Model 6, adjusted for model 5 plus body mass index.

\section{Associations of individual components of MetS with TT and serum Hcy levels}

The associations of TT and serum Hcy quartiles with each component of MetS were assessed after adjusting for age, alcohol consumption, smoking status, hs-CRP, and HOMA-IR (Table 5). TT quartile remained significantly associated with high $\mathrm{WC}$, high TG, and low HDL-C levels $(P<0.001)$. However, serum Hcy quartile was only significantly associated with WC $(P=$ 0.021). After adjusting for BMI, the associations of TT and se- rum Hcy quartile with WC were no longer significant (data not shown).

\section{DISCUSSION}

We observed that TT levels were significantly associated with MetS after adjusting for age, alcohol consumption, smoking status, hs-CRP, HOMA-IR, and BMI. In addition, TT levels were associated with the individual MetS components of high 
Table 5. Age-Adjusted Odds Ratios of Metabolic Syndrome Components Depending on Total Testosterone and Serum Homocysteine Quartiles

\begin{tabular}{|c|c|c|c|c|c|c|c|c|}
\hline & & Tota & sterone & & & Serun & ysteine & \\
\hline & Q4 & Q3 & Q2 & Q1 & Q4 & Q3 & Q2 & Q1 \\
\hline High BP & 1.000 & & & & 1.000 & & & \\
\hline $\operatorname{Exp}(B)$ & & 1.015 & 0.976 & 1.016 & & 0.977 & 1.025 & 1.122 \\
\hline Lower & & 0.866 & 0.833 & 0.868 & & 0.838 & 0.880 & 0.964 \\
\hline Upper & & 1.189 & 1.143 & 1.190 & & 1.140 & 1.195 & 1.305 \\
\hline$P$ value & & 0.854 & 0.762 & 0.845 & & 0.771 & 0.751 & 0.138 \\
\hline High glucose & 1.000 & & & & 1.000 & & & \\
\hline $\operatorname{Exp}(B)$ & & 0.938 & 0.857 & 0.792 & & 0.925 & 0.890 & 0.691 \\
\hline Lower & & 0.806 & 0.736 & 0.680 & & 0.801 & 0.770 & 0.594 \\
\hline Upper & & 1.092 & 0.997 & 0.923 & & 1.069 & 1.030 & 0.802 \\
\hline$P$ value & & 0.408 & 0.046 & 0.003 & & 0.291 & 0.117 & $<0.001$ \\
\hline Waist circumference & 1.000 & & & & 1.000 & & & \\
\hline $\operatorname{Exp}(B)$ & & 1.725 & 2.139 & 3.043 & & 1.139 & 1.211 & 1.203 \\
\hline Lower & & 1.438 & 1.789 & 2.554 & & 0.972 & 1.035 & 1.028 \\
\hline Upper & & 2.070 & 2.557 & 3.627 & & 1.333 & 1.418 & 1.407 \\
\hline$P$ value & & $<0.001$ & $<0.001$ & $<0.001$ & & 0.107 & 0.017 & 0.021 \\
\hline High TG & 1.000 & & & & 1.000 & & & \\
\hline $\operatorname{Exp}(B)$ & & 1.294 & 1.675 & 2.067 & & 0.922 & 0.829 & 0.782 \\
\hline Lower & & 1.117 & 1.449 & 1.789 & & 0.807 & 0.724 & 0.682 \\
\hline Upper & & 1.500 & 1.935 & 2.389 & & 1.054 & 0.950 & 0.897 \\
\hline$P$ value & & 0.001 & $<0.001$ & $<0.001$ & & 0.233 & 0.007 & $<0.001$ \\
\hline Low HDL-C & 1.000 & & & & 1.000 & & & \\
\hline $\operatorname{Exp}(B)$ & & 1.363 & 1.997 & 2.729 & & 1.007 & 0.922 & 0.949 \\
\hline Lower & & 1.135 & 1.678 & 2.301 & & 0.864 & 0.789 & 0.813 \\
\hline Upper & & 1.636 & 2.376 & 3.236 & & 1.173 & 1.078 & 1.108 \\
\hline$P$ value & & 0.001 & $<0.001$ & $<0.001$ & & 0.932 & 0.309 & 0.507 \\
\hline
\end{tabular}

High BP, $\geq 130 / 85 \mathrm{~mm} \mathrm{Hg}$ or medication; high glucose, fasting plasma glucose $\geq 100 \mathrm{mg} / \mathrm{dL}$ or type 2 diabetes mellitus; high TG, $\geq 150 \mathrm{mg} / \mathrm{dL}$; low HDL-C, $<40 \mathrm{mg} / \mathrm{dL}$.

BP, blood pressure; TG, triglyceride; HDL-C, high density lipoprotein cholesterol.

WC, hypertriglyceridemia, and low HDL.

The findings of a relationship between TT and MetS, even after adjusting for multiple confounders, are consistent with the results of numerous epidemiological studies. When adjusting for BMI and HOMA-IR, the strength of the associations decreased appreciably but remained significant, suggesting that these factors play a role in the observed associations. Muller et al. [17] found that higher testosterone levels were associated with a reduced risk of MetS independently of insulin level and BMI. A cross-sectional study in Korea reported that TT was negatively associated with the prevalence of MetS independently of BMI [18]. Brand et al. [3] re-analyzed data from 20 observational studies and found that the relationship between TT and
MetS prevalence was attenuated, but remained significant, after adjusting for HOMA-IR. Moreover, a prospective study by Laaksonen et al. [7] indicated that low TT independently predicted MetS development in middle-aged men after adjusting for BMI and insulin concentration.

Testosterone is secreted by Leydig cells via the hypothalamicpituitary-testicular axis. High aromatase activity in adipocytes increases the conversion of testosterone to estradiol and facilitates TG storage in adipocytes, increasing lipoprotein lipase activity [19]. The resulting increase in the size and number of adipocytes leads to insulin resistance. Increased levels of free fatty acids and insulin resistance lead to hypertriglyceridemia and an increased hepatic lipase level $[19,20]$. The level of hepatic li- 
pase determines both the level of HDL-C and its function in reverse cholesterol transport [21]. Additionally, in men with type 2 DM, low HDL-C is associated with TT and the androgen receptor CAG repeat polymorphism [22,23]. These findings may provide an explanation for the higher CVD risk in men with lower TT levels. However, the exact mechanism by which testosterone levels affect lipid profiles is still not known.

Considering the individual components of MetS, we observed an inverse relationship between TT and the number of MetS components present. Additionally, MetS components were associated with unfavorable profiles, including increased TG and decreased HDL-C, after fully adjusting for confounding factors. However, the relationship between TT and MetS components, such as hypertension and high glucose, was not significant after adjusting for HOMA-IR. According to previous cross-sectional studies, the associations with TT are strongest for prevalent abdominal obesity and dyslipidemia and weakest for prevalent hypertension $[3,24]$. In the present study, we found that insulin resistance mediated hypertension and high glucose levels.

The inverse relationship between TT levels and MetS is consistent across races and ethnicities [24]. In a previous study, Whites were found to have higher correlation than Blacks or Hispanics, but the differences were not significant. As mentioned above, of the MetS components, WC and dyslipidemia showed stronger association with TT levels than other factors. These results have generally been largely consistent across races and ethnicities. Similar patterns have been observed in our study and in other studies in Korea and Japan [18,25]. However, the TT levels reported in the other two studies were lower than those found in the present study. This discrepancy is most likely due to differences in the age range of participants. No significant differences in TT levels have been found across racial or ethnic groups, with the exception of a study that found that TT levels in Asians were significantly lower than those of other races in people older than 65 years [26,27].

We found that serum Hcy levels were not associated with MetS. However, many studies have reported conflicting results regarding this association. In a longitudinal study of Chinese individuals who underwent a routine health check-up, plasma total Hcy levels were higher in individuals with MetS than in those without MetS, but were not associated with the incidence of MetS [14]. The mean age and Hcy levels were higher in this previous study than in the present study $(61.40 \pm 11.40$ years vs. $40.86 \pm$ 9.41 years and $18.41 \pm 8.23 \mu \mathrm{mol} / \mathrm{L}$ vs. $11.26 \pm 4.40 \mu \mathrm{mol} / \mathrm{L}$, respectively). In other studies, serum Hcy has been found to be associated with MetS in individuals with hypertension, obesity, and DM with complications [28-30]. However, the participants in our study were generally healthy and received regular health check-ups. In the Iranian general population, there was no significant difference in serum Hcy levels between individuals with or without MetS and no association between serum Hcy levels and MetS [31]. In healthy premenopausal women, plasma Hcy was not associated with insulin resistance or MetS [32]. In terms of racial and ethnic differences, Whites had higher Hcy levels than Blacks and Mexican Americans [33]. This can be attributed to a point mutation in the gene that encodes $\mathrm{N}^{5}, \mathrm{~N}^{10}$ methylenetetrahydrofolate reductase (MTHFR), because the point mutation in the MTHFR gene is more common in Whites than in Blacks [34]. The $\mathrm{C} \rightarrow \mathrm{T}$ substitution at nucleotide 677 results in a thermolabile form with reduced activity that leads to increased Hcy levels. In studies conducted in Canada and England, Hcy levels were significantly higher in South Asians than in Caucasians and East Asians [35-37]. Additionally, LDL-C, HDL-C, TG, BMI, diastolic BP, and glucose levels were significantly higher than in other races [36]. This phenomenon is thought to be caused by the vegetarian diet characteristic of religious Hindus or by genetic mutations including MTHFR $[35,37]$. In contrast, East Asians have somewhat lower Hcy levels. Nevertheless, studies in China or Iran have shown no association with MetS $[14,31,38]$. This discrepancy is presumed to be caused by differences in study design, diet, and genetic mutations. In a cross-sectional study conducted in Korea, there was no association between Hcy levels and MetS, consistent with our results [39]. Therefore, the existence of conflicting reports may have been due to differences among study populations in age, ethnicity, PA, dietary factors, sex, and study design.

In the present study, WC was the only MetS component that was associated with serum Hcy. In a study of a Korean population, the waist-hip ratio was associated with hyperhomocysteinemia [40]. Vaya et al. [41] reported that only the metabolic component of abdominal obesity was associated with Hcy in obese patients, and that abdominal obesity was an independent predictor of hyperhomocysteinemia. However, some studies reported no significant correlation, or an inverse relationship, between abdominal obesity and Hcy $[28,29,42]$. These discrepancies may have been due to differences in study populations. In the present study, although HOMA-IR and insulin were significantly higher in participants with MetS than in those without MetS, serum Hcy did not differ significantly depending on the presence of MetS and was associated with WC independently of insulin resistance. Several studies show that Hcy levels in healthy individuals are not associated with insulin resistance $[32,43,44]$. 
Therefore, serum Hcy levels could serve as a marker of abdominal obesity in generally healthy individuals.

The mechanism underlying the relationship between hyperhomocysteinemia and abdominal obesity is not yet clear. There is an inverse relationship between folate and BMI [45,46], leading us to speculate that Hcy levels are increased by reductions in folate and have a proportional relationship with abdominal obesity. In addition, in a study of mice with nonalcoholic fatty liver disease induced by high-calorie food intake, Hcy levels were increased by downregulation of hepatic cystathionine $\beta$-synthase and $\beta$-lyase, which are involved in the transsulfuration pathway in the liver [47].

We found that FPG was inversely related to serum Hcy levels. Despite the positive association between insulin resistance and Hcy, some research has shown Hcy levels to be lower in healthy individuals with insulin resistance than in the general population and that Hcy levels decreased in response to hyperfiltration of the kidney in the early stage of diabetic nephropathy without severe complications $[48,49]$. Our finding is presumably due to the exclusion of individuals with renal impairment from our study.

Exercise is generally accepted to be a key component of the treatment and prevention of MetS. PA has beneficial effects on BP, WC, and lipid profiles [50]. However, in our study, there was no significant difference in the amount of exercise performed by participants with or without MetS. This finding may be because participants with MetS exercised vigorously or moderately as a means of improving their health through lifestyle modifications.

In this large population-based study, we evaluated the relationships of TT and serum Hcy levels with MetS, including its individual components, after adjusting for multiple potential confounding factors. However, our study has some limitations. First, we could not establish causal relationships because of the cross-sectional study design. Second, our sample cannot be considered representative of the general population, as it included only healthy male workers. Third, the single determination of TT and serum Hcy levels may have resulted in the misclassification of participants. Fourth, the criteria used to define MetS may be different for different ethnic groups. Fifth, dietary factors such as vitamin B12, vitamin B6, and folate, which affect fasting Hcy levels, were not measured or reported.

In conclusion, we suggest that TT is a strong predictor of MetS and that serum Hcy levels could serve as a marker of abdominal obesity. However, further research on the pathogenesis of MetS, including prospective studies, is required.

\section{CONFLICTS OF INTEREST}

No potential conflict of interest relevant to this article was reported.

\section{ACKNOWLEDGMENTS}

This study was funded by a grant from the Korea Hydro \& Nuclear Power Project (A17LF02).

\section{AUTHOR CONTRIBUTIONS}

Conception or design: S.J.C. Acquisition, analysis, or interpretation of data: S.H.S., N.H.K., J.K.L. Drafting the work or revising: S.H.S., S.P.H., S.J.C. Final approval of the manuscript: S.J.C.

\section{ORCID}

Sook Hee Sung https://orcid.org/0000-0001-8308-2301

Nam Hee Kim https://orcid.org/0000-0001-5378-6260

Sun Pyo Hong https://orcid.org/0000-0001-8882-5901

Jong-Keun Lee https://orcid.org/0000-0003-1376-3202

Seung Jin Choi https://orcid.org/0000-0002-4488-187X

\section{REFERENCES}

1. Lim S, Shin H, Song JH, Kwak SH, Kang SM, Won Yoon J, et al. Increasing prevalence of metabolic syndrome in Korea: the Korean National Health and Nutrition Examination Survey for 1998-2007. Diabetes Care 2011;34:1323-8.

2. Andreadis EA, Tsourous GI, Tzavara CK, Georgiopoulos DX, Katsanou PM, Marakomichelakis GE, et al. Metabolic syndrome and incident cardiovascular morbidity and mortality in a Mediterranean hypertensive population. Am J Hypertens 2007;20:558-64.

3. Brand JS, Rovers MM, Yeap BB, Schneider HJ, Tuomainen TP, Haring R, et al. Testosterone, sex hormone-binding globulin and the metabolic syndrome in men: an individual participant data meta-analysis of observational studies. PLoS One 2014;9:e100409.

4. Haring R, Volzke H, Felix SB, Schipf S, Dorr M, Rosskopf $\mathrm{D}$, et al. Prediction of metabolic syndrome by low serum testosterone levels in men: results from the study of health in Pomerania. Diabetes 2009;58:2027-31.

5. Li C, Ford ES, Li B, Giles WH, Liu S. Association of testos- 
terone and sex hormone-binding globulin with metabolic syndrome and insulin resistance in men. Diabetes Care 2010;33:1618-24.

6. Kupelian V, Page ST, Araujo AB, Travison TG, Bremner WJ, McKinlay JB. Low sex hormone-binding globulin, total testosterone, and symptomatic androgen deficiency are associated with development of the metabolic syndrome in nonobese men. J Clin Endocrinol Metab 2006;91:843-50.

7. Laaksonen DE, Niskanen L, Punnonen K, Nyyssonen K, Tuomainen TP, Valkonen VP, et al. Testosterone and sex hormone-binding globulin predict the metabolic syndrome and diabetes in middle-aged men. Diabetes Care 2004;27: 1036-41.

8. Yeap BB, Chubb SA, Hyde Z, Jamrozik K, Hankey GJ, Flicker L, et al. Lower serum testosterone is independently associated with insulin resistance in non-diabetic older men: the Health In Men Study. Eur J Endocrinol 2009;161:591-8.

9. Tsai EC, Boyko EJ, Leonetti DL, Fujimoto WY. Low serum testosterone level as a predictor of increased visceral fat in Japanese-American men. Int J Obes Relat Metab Disord 2000;24:485-91.

10. Rao PM, Kelly DM, Jones TH. Testosterone and insulin resistance in the metabolic syndrome and T2DM in men. Nat Rev Endocrinol 2013;9:479-93.

11. Fonseca V, Guba SC, Fink LM. Hyperhomocysteinemia and the endocrine system: implications for atherosclerosis and thrombosis. Endocr Rev 1999;20:738-59.

12. Wald DS, Law M, Morris JK. Homocysteine and cardiovascular disease: evidence on causality from a meta-analysis. BMJ 2002;325:1202.

13. Meigs JB, Jacques PF, Selhub J, Singer DE, Nathan DM, Rifai N, et al. Fasting plasma homocysteine levels in the insulin resistance syndrome: the Framingham offspring study. Diabetes Care 2001;24:1403-10.

14. Wang X, Ye P, Cao R, Yang X, Xiao W, Zhang Y, et al. The association of homocysteine with metabolic syndrome in a community-dwelling population: homocysteine might be concomitant with metabolic syndrome. PLoS One 2014;9: e113148.

15. Alberti KG, Eckel RH, Grundy SM, Zimmet PZ, Cleeman JI, Donato KA, et al. Harmonizing the metabolic syndrome: a joint interim statement of the International Diabetes Federation Task Force on Epidemiology and Prevention; National Heart, Lung, and Blood Institute; American Heart Association; World Heart Federation; International Atherosclerosis Society; and International Association for the Study of
Obesity. Circulation 2009;120:1640-5.

16. Lee SY, Park HS, Kim DJ, Han JH, Kim SM, Cho GJ, et al. Appropriate waist circumference cutoff points for central obesity in Korean adults. Diabetes Res Clin Pract 2007;75: 72-80.

17. Muller M, Grobbee DE, den Tonkelaar I, Lamberts SW, van der Schouw YT. Endogenous sex hormones and metabolic syndrome in aging men. J Clin Endocrinol Metab 2005;90: 2618-23.

18. Hong D, Kim YS, Son ES, Kim KN, Kim BT, Lee DJ, et al. Total testosterone and sex hormone-binding globulin are associated with metabolic syndrome independent of age and body mass index in Korean men. Maturitas 2013;74:148-53.

19. Cohen PG. The hypogonadal-obesity cycle: role of aromatase in modulating the testosterone-estradiol shunt: a major factor in the genesis of morbid obesity. Med Hypotheses 1999;52:49-51.

20. Chatterjee C, Sparks DL. Hepatic lipase, high density lipoproteins, and hypertriglyceridemia. Am J Pathol 2011;178: 1429-33.

21. Thuren T. Hepatic lipase and HDL metabolism. Curr Opin Lipidol 2000;11:277-83.

22. Van Pottelbergh I, Braeckman L, De Bacquer D, De Backer G, Kaufman JM. Differential contribution of testosterone and estradiol in the determination of cholesterol and lipoprotein profile in healthy middle-aged men. Atherosclerosis 2003;166:95-102.

23. Stanworth RD, Kapoor D, Channer KS, Jones TH. Dyslipidaemia is associated with testosterone, oestradiol and androgen receptor CAG repeat polymorphism in men with type 2 diabetes. Clin Endocrinol (Oxf) 2011;74:624-30.

24. Kupelian V, Hayes FJ, Link CL, Rosen R, McKinlay JB. Inverse association of testosterone and the metabolic syndrome in men is consistent across race and ethnic groups. J Clin Endocrinol Metab 2008;93:3403-10.

25. Akishita M, Fukai S, Hashimoto M, Kameyama Y, Nomura K, Nakamura T, et al. Association of low testosterone with metabolic syndrome and its components in middle-aged Japanese men. Hypertens Res 2010;33:587-91.

26. Litman HJ, Bhasin S, Link CL, Araujo AB, McKinlay JB. Serum androgen levels in black, Hispanic, and white men. J Clin Endocrinol Metab 2006;91:4326-34.

27. Orwoll E, Lambert LC, Marshall LM, Phipps K, Blank J, Barrett-Connor E, et al. Testosterone and estradiol among older men. J Clin Endocrinol Metab 2006;91:1336-44.

28. Catena C, Colussi G, Nait F, Capobianco F, Sechi LA. Ele- 
vated homocysteine levels are associated with the metabolic syndrome and cardiovascular events in hypertensive patients. Am J Hypertens 2015;28:943-50.

29. Sreckovic B, Sreckovic VD, Soldatovic I, Colak E, Sumarac-Dumanovic M, Janeski $\mathrm{H}$, et al. Homocysteine is a marker for metabolic syndrome and atherosclerosis. Diabetes Metab Syndr 2017;11:179-82.

30. Buysschaert M, Dramais AS, Wallemacq PE, Hermans MP. Hyperhomocysteinemia in type 2 diabetes: relationship to macroangiopathy, nephropathy, and insulin resistance. Diabetes Care 2000;23:1816-22.

31. Nabipour I, Ebrahimi A, Jafari SM, Vahdat K, Assadi M, Movahed A, et al. The metabolic syndrome is not associated with homocysteinemia: the Persian Gulf Healthy Heart Study. J Endocrinol Invest 2009;32:406-10.

32. Tanrikulu-Kilic F, Bekpinar S, Unlucerci Y, Orhan Y. Insulin resistance is not related to plasma homocysteine concentration in healthy premenapausal women. Physiol Res 2006;55: 285-90.

33. Ganji V, Kafai MR; Third National Health and Nutrition Examination Survey. Demographic, health, lifestyle, and blood vitamin determinants of serum total homocysteine concentrations in the third National Health and Nutrition Examination Survey, 1988-1994. Am J Clin Nutr 2003;77:826-33.

34. McAndrew PE, Brandt JT, Pearl DK, Prior TW. The incidence of the gene for thermolabile methylene tetrahydrofolate reductase in African Americans. Thromb Res 1996;83: 195-8.

35. Senaratne MP, MacDonald K, De Silva D. Possible ethnic differences in plasma homocysteine levels associated with coronary artery disease between south Asian and east Asian immigrants. Clin Cardiol 2001;24:730-4.

36. Anand SS, Yusuf S, Vuksan V, Devanesen S, Teo KK, Montague PA, et al. Differences in risk factors, atherosclerosis and cardiovascular disease between ethnic groups in Canada: the study of health assessment and risk in ethnic groups (SHARE). Indian Heart J 2000;52:S35-43.

37. Cappuccio FP, Bell R, Perry IJ, Gilg J, Ueland PM, Refsum $\mathrm{H}$, et al. Homocysteine levels in men and women of different ethnic and cultural background living in England. Atherosclerosis 2002;164:95-102.

38. Esteghamati A, Hafezi-Nejad N, Zandieh A, Sheikhbahaei S, Ebadi M, Nakhjavani M. Homocysteine and metabolic syndrome: from clustering to additional utility in prediction of coronary heart disease. J Cardiol 2014;64:290-6.

39. Rhee EJ, Hwang ST, Lee WY, Yoon JH, Kim BJ, Kim BS, et al. Relationship between metabolic syndrome categorized by newly recommended by International Diabetes Federation criteria with plasma homocysteine concentration. Endocr J 2007;54:995-1002.

40. Shin KA. Association between obesity factors and homocysteine levels with the metabolic syndrome. Korean J Clin Lab Sci 2012;44:147-54.

41. Vaya A, Rivera L, Hernandez-Mijares A, de la Fuente M, Sola E, Romagnoli M, et al. Homocysteine levels in morbidly obese patients: its association with waist circumference and insulin resistance. Clin Hemorheol Microcirc 2012;52:49-56.

42. Park SB, Georgiades A. Changes in body composition predict homocysteine changes and hyperhomocysteinemia in Korea. J Korean Med Sci 2013;28:1015-20.

43. Abbasi F, Facchini F, Humphreys MH, Reaven GM. Plasma homocysteine concentrations in healthy volunteers are not related to differences in insulin-mediated glucose disposal. Atherosclerosis 1999;146:175-8.

44. Godsland IF, Rosankiewicz JR, Proudler AJ, Johnston DG. Plasma total homocysteine concentrations are unrelated to insulin sensitivity and components of the metabolic syndrome in healthy men. J Clin Endocrinol Metab 2001;86: 719-23.

45. Nakazato M, Maeda T, Takamura N, Wada M, Yamasaki H, Johnston KE, et al. Relation of body mass index to blood folate and total homocysteine concentrations in Japanese adults. Eur J Nutr 2011;50:581-5.

46. Mojtabai R. Body mass index and serum folate in childbearing age women. Eur J Epidemiol 2004;19:1029-36.

47. Bravo E, Palleschi S, Aspichueta P, Buque X, Rossi B, Cano A, et al. High fat diet-induced non alcoholic fatty liver disease in rats is associated with hyperhomocysteinemia caused by down regulation of the transsulphuration pathway. Lipids Health Dis 2011;10:60.

48. Fonseca VA, Mudaliar S, Schmidt B, Fink LM, Kern PA, Henry RR. Plasma homocysteine concentrations are regulated by acute hyperinsulinemia in nondiabetic but not type 2 diabetic subjects. Metabolism 1998;47:686-9.

49. Rosolova H, Simon J, Mayer O Jr, Racek J, Dierze T, Jacobsen DW. Unexpected inverse relationship between insulin resistance and serum homocysteine in healthy subjects. Physiol Res 2002;51:93-8.

50. Pitsavos C, Panagiotakos D, Weinem M, Stefanadis C. Diet, exercise and the metabolic syndrome. Rev Diabet Stud 2006;3:118-26. 